\title{
Hybridization and Self-compatibility in Celtis: AFLP Analysis of Controlled Crosses
}

\author{
Alan T. Whittemore ${ }^{1}$ and Alden M. Townsend \\ United States National Arboretum, 3501 New York Avenue NE, Washington, D.C. 20002-1958
}

\begin{abstract}
AdDitional INDEX wORDS. hackberry, sugarberry, Cannabaceae, interspecific hybrids, urban tree breeding
Abstract. Artificial cross-pollinations were carried out among seven species of Celtis L. (C. bungeana Blume, C. koraiensis Nakai, C. laevigata Willd., C. occidentalis L., C. reticulata Torr., $C$. sinensis Pers., and $C$. tenuifolia Nutt.) to test the potential for interspecific hybridization in Celtis breeding. AFLP profiles were used to assess the ancestry of progeny. Hybrids formed very rarely among these seven species of Celtis: only two interspecific hybrids were obtained. Self-pollination occurred occasionally in non-emasculated trees. AFLP analysis yielded false paternal markers at a very low frequency, likely due to DNA methylation differences. Plants with unexpected paternal markers were confidently distinguished from hybrids by calculating the probability of obtaining the observed number of paternal markers by chance. The study clearly demonstrated the importance of using large numbers of markers.
\end{abstract}

The genus Celtis (hackberries and sugarberries) is a group of trees with much promise for horticulture. Some of the American species, especially Celtis occidentalis and Celtis reticulata, are fast-growing trees with great tolerance to heat, cold, drought, periodic flooding, rapid changes in temperature and moisture, and a variety of soil types, making them very useful trees for arid or semi-arid regions with extreme temperature fluctuations (especially the western Great Plains and intermountain western United States) and promising for difficult urban habitats (Dirr, 1998; Krajicek, 1965; Krajicek and Williams, 1990). Celtis species often are recommended for attracting wildlife because the fruits are eaten by many bird species.

Use of hackberries as landscape trees has been limited by susceptibility to several pathogens. Hackberries are susceptible to witches' brooms [incited by a mite (Eriophyes Siebold) and a powdery mildew (Sphaerotheca phytoptophila Kellerm. \& Swingle)] and leaf galls (incited by a species of the hemipteran genus Pachypsylla Riley). Although these pathogens do not harm the plant, they can seriously disfigure it (Dirr, 1998; Elias, 1970). Several Celtis species native to eastern Asia are coming into use in American horticulture, and at least some of these Asian species are not susceptible to galls or witches' brooms. These species lack the extreme tolerance to environmental stress that is found in native American germplasm, but they are a potential source of disease-resistance genes for tolerant species.

Interspecific hybridization experiments have not been carried out in Celtis. Species of Celtis have often been presumed to hybridize based on patterns of variation observed in wild populations (Fernald, 1950; Mitchell, 1988; Wofford and Chester, 2002), but one recent study found no evidence of interspecific hybridization in wild populations of Celtis laevigata and $C$. reticulata (Whittemore, 2005).

We carried out cross-pollinations among seven Celtis species (C. bungeana, C. koraiensis, C. laevigata, C. occidentalis,

Received for publication 5 Dec. 2005. Accepted for publication 27 Jan. 2007. We thank Blandy Experimental Farm and the Maryland Book Exchange for permission to make crosses or gather pollen on their land, Louise Riedel and Sue Bentz for their excellent work in the laboratory, fields, and greenhouses, and Alan Meerow, Susan Wiegrefe, and Margaret Pooler for helpful comments on the manuscript.

${ }^{1}$ Corresponding author. E-mail: alan.whiteemore@ars.usda.gov.
C. reticulata, C. sinensis, and C. tenuifolia) to test the potential for interspecific hybridization in breeding for pathogen resistance in the genus.

The genus Celtis was traditionally placed in Ulmaceae (Mabberley, 1997), a group of plants that are commonly selfincompatible, but recent work indicates that the relationship between Celtis and Ulmus L. is not as close as was once believed, and Celtis is now placed in the related family Cannabaceae (Song et al., 2001; Sytsma et al., 2002; Wiegrefe et al., 1998). Hackberries have sometimes been considered self-compatible based on the abstract of Boonpragob (1972), but no documentation supporting this report has ever been published. Because Celtis flowers are numerous and small, with the stamens and styles often very close together, emasculation would add considerably to the time and labor required for a program of controlled hybridization. Flowers mature sequentially over a period of $\approx 2$ weeks, so complete emasculation would require opening bagged stems more than once, increasing the potential for contamination with wind-borne pollen. To test how often selfing could occur in bagged, nonemasculated branches, we left the anthers to open in place and evaluated progeny to see if they resulted from self-pollination.

It is difficult to use morphology to evaluate hybridity in Celtis because the juvenile foliage of many Celtis species has a very different morphology than the adult foliage, and this juvenile morphology usually persists until the plant is $1-2 \mathrm{~m}$ in height. Amplified fragment length polymorphism (AFLP) studies using large numbers of markers have shown promise for detecting hybrids (Pooler et al., 2002). AFLP markers were used to assess the parentage of progeny of controlled pollinations and to assess the usefulness of AFLPs for identifying hybrid progeny too young for morphological study.

\section{Materials and Methods}

Plant material. Fourteen plants belonging to seven species were used as parents (Table 1). A few pollinations were carried out in 1994, 1995, and 1998, but the bulk of seedlings discussed in this study were derived from crosses made in 1999.

ConTrolled Crosses. About a month before normal anthesis, mature branches were brought inside the greenhouse to force pollen shed. Pollen was collected on waxed paper, 
Table 1. Plants used as parents in crossing experiments.

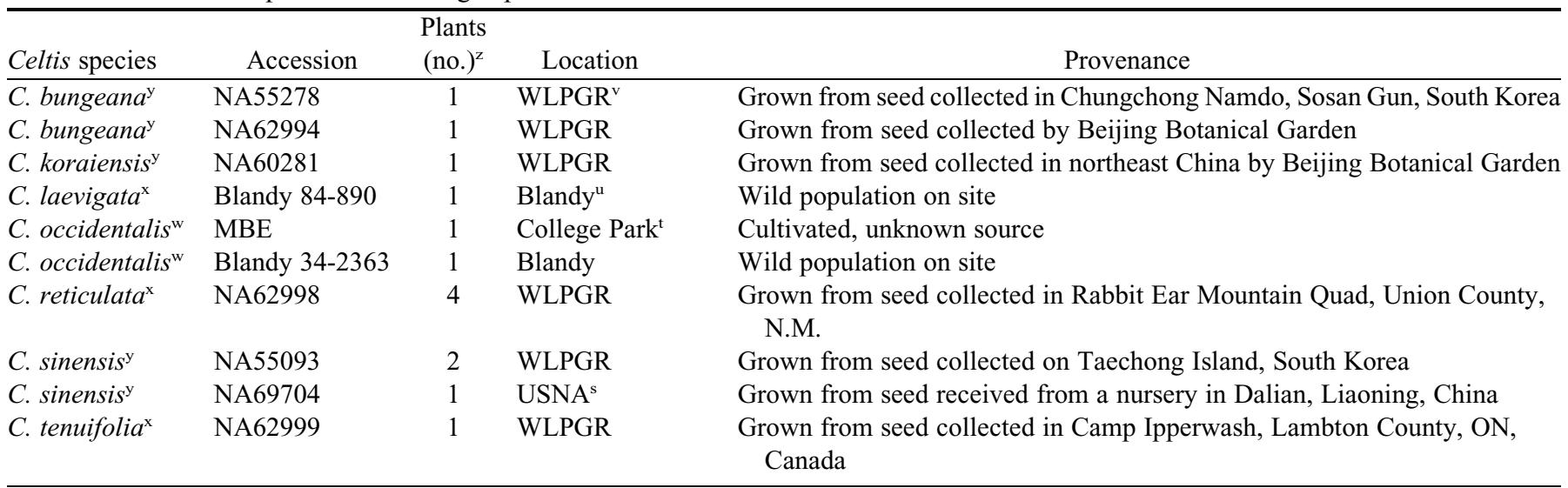

${ }^{\mathrm{z}}$ Number of trees of each accession that were used as a pollen donor or recipient in any experiment.

${ }^{\mathrm{y}}$ Resistant to witches' brooms and leaf galls.

'Resistant to witches' brooms, susceptible to leaf galls (preliminary findings).

"Susceptible to witches' brooms and leaf galls (preliminary findings).

'U.S. Department of Agriculture Woody Landscape Plant Germplasm Repository in Prince George's Co., Md.

"Orland E. White Arboretum of Blandy Farm, Boyce, Va.

${ }^{\mathrm{t}}$ City of College Park, Md.

sUnited States National Arboretum, Washington, D.C.

transferred to plastic vials, and then stored at $4{ }^{\circ} \mathrm{C}$. About $7 \mathrm{~d}$ before natural flowering occurred on trees designated as female parents, white nonwoven polyester pollination bags (Plant Breeding Supplies International, Scarborough, England) were placed over the ends of branches to enclose the unopened flower buds. Once the flowers began to open, slits were cut in the bags, and pollen was transferred with an artist's brush to the flowers inside the bag. Afterward, the pollination bags were sealed with adhesive tape and left on the tree. Pollination of the same flowers was repeated when possible on one or more dates to ensure the best chances for effective fertilization. For selfing trials, clean artists' brushes were used to transfer pollen from anthers to stigmas within the same bag, in the same manner as with the controlled crosses.

Pollination bags were removed $\approx 1$ month before fruit maturation and replaced with open-weave mesh bags. When ripe, the fruit were collected and planted in greenhouse flats for cold stratification and later germination. About 2 months after germination, seedlings were transplanted to 7.6-L containers into a 4 perlite : 2 Metro-Mix 510 (Sun Gro, Vancouver, B.C.) : 1 peatmoss (by volume) medium and grown outside.

DNA extraction. New half-expanded leaf tissue was collected and placed in plastic bags in a cooler. Tissue was placed in a $-70{ }^{\circ} \mathrm{C}$ freezer within $3 \mathrm{~h}$ of collection. Samples were freeze-dried for $48-72 \mathrm{~h}$ under vacuum and stored at $-70{ }^{\circ} \mathrm{C}$ until use. Samples of leaf tissue were extracted in CTAB buffer (Whittemore, 2005).

AFLP GENOTYPING. AFLP electropherograms were generated for each sample using protocols described by Vos et al. (1995) with modifications. Samples were analyzed on an ABI 310 genetic analyzer (Applied Biosystems, Foster City, Calif.).

DNA restriction and ligation were sequential rather than simultaneous, using $25 \mu \mathrm{g}$ of genomic DNA. Restriction was performed at $37^{\circ} \mathrm{C}$ for $2 \mathrm{~h}$. Ligations of adaptors were carried out at $20^{\circ} \mathrm{C}$ for $2 \mathrm{~h}$, then diluted to $200 \mu \mathrm{L}$ total volume.

Preselective amplifications used the primers EcoRI (5' GACTGCGTACCAATTCA 3') and MseI (5' GATGAGTCC
TGAGTAAC $3^{\prime}$ ). Reactions were carried out in $50-\mu \mathrm{L}$ volumes containing $5 \mu \mathrm{L}$ of $10 \times$ PCR buffer (Invitrogen, Carlsbad, Calif.), $1.5 \mathrm{~mm} \mathrm{MgCl}_{2}, 50 \mu \mathrm{M}$ dNTP, $0.1125 \mu \mathrm{m}$ each of preselective primer, 5.0 U of Taq DNA polymerase recombinant (Invitrogen), and $5 \mu \mathrm{L}$ of diluted restriction/ligation reaction. Amplification reactions were carried out on a Biometra T3 thermocycler (Göttingen, Germany) programmed for $2 \mathrm{~min}$ at $72{ }^{\circ} \mathrm{C}, 2$ min at $94{ }^{\circ} \mathrm{C}$ followed by 30 cycles of $30 \mathrm{~s}$ at $94{ }^{\circ} \mathrm{C}$, $1 \mathrm{~min}$ at $60{ }^{\circ} \mathrm{C}$, and $2 \mathrm{~min}$ at $72{ }^{\circ} \mathrm{C}$ with a final extension for $10 \mathrm{~min}$ at $72{ }^{\circ} \mathrm{C}$. Aliquots of $5 \mu \mathrm{L}$ of diluted preselective reactions $(3 \mu \mathrm{L}$ of preselective reaction with $147 \mu \mathrm{L}$ of $\mathrm{TE}$ buffer) were used as template for all selective reactions.

Selective amplification used primer pairs with the general primer seqences of EcoRI (5' GACTGCGTACCAATTCXXX 3') and $\mathrm{Mse}$ ( $5^{\prime}$ GATGAGTCCTGAGTAAYYY $3^{\prime}$ ), where the various primer pairs differ in their sequences at -XXX and -YYY (Vos et al., 1995). Nine primer pairs were used, with -XXX/-YYY as follows: -AAC/-CTC, -AAG/-CTC, -ACG/-CAC, -ACG/ -CTC, -ACT/-CTC, -AGC/-CAC, -AGC/-CTC, -AGG/-CAT, and -AGG/-CTG. Reactions were carried out in $20-\mu \mathrm{L}$ volumes containing $1 \times$ PCR buffer (Invitrogen), $100 \mu \mathrm{M}$ dNTP, $1.5 \mathrm{~mm}$ $\mathrm{MgCl}_{2}, 0.25 \mu \mathrm{M}$ MseI primers, 0.1 $\mu \mathrm{M}$ EcoRI primers, and $0.5 \mathrm{U}$ of $\mathrm{Taq}$ DNA polymerase recombinant (Invitrogen). The EcoRI selective primers had fluorescently labeled $5^{\prime}$ ends and were purchased from the Applied Biosystems Custom Oligonucleotide Synthesis Service. Amplification reactions were run on a Biometra $\mathrm{T} 3$ thermocycler programmed for 13 cycles of $30 \mathrm{~s}$ at $94^{\circ} \mathrm{C}, 30 \mathrm{~s}$ at $65-56.6^{\circ} \mathrm{C}$ (decreasing $0.7^{\circ} \mathrm{C}$ each cycle), and $1 \mathrm{~min}$ at $72^{\circ} \mathrm{C}$ followed by 23 cycles of $30 \mathrm{~s}$ at $94{ }^{\circ} \mathrm{C}, 30 \mathrm{~s}$ at $56^{\circ} \mathrm{C}$, and $1 \mathrm{~min}$ at $72{ }^{\circ} \mathrm{C}$.

Samples were analyzed on an ABI 310 genetic analyzer and scored with Genotyper 2.5 software as described by Whittemore (2005). Sample preparation from DNA extract through all selective reactions was repeated for all parent samples and $10 \%$ of the progeny to ensure repeatability; and for each putative hybrid combination tested for, a sample consisting of $0.5 \mu \mathrm{L}$ of each of the two parental selective 
reactions mixed together was run to ensure that loci were reliably detectable at reduced doses.

Determination of PATERnity. AFLP markers were used to determine the paternity of the seedlings obtained from all cross-pollinations. The probability that a given AFLP peak that is present in only one parent of a cross will be inherited by a hybrid offspring is $P=0.5$ if the parent is heterozygous and $P=1$ if it is homozygous. If $n$ such marker loci are identified, then the expected number of peaks in a hybrid offspring varies from $n$ (if all loci are homozygous in the parent that carries them) to $n / 2$ (if all are heterozygous).

If small numbers of putative paternal markers are observed (i.e., many fewer than half of the markers present in the putative pollen donor), then the hypothesis that the seedlings are actually progeny of the pollen donor must be tested by calculating the probability of obtaining such a small number of markers in true progeny of the putative parent through random assortment among the loci. If the probability is less than $P=$ 0.05 , then the hypothesis that the pollen donor is the male parent should be rejected, and alternate origins of the peaks in question, such as methylation differences or recombination within the maternal genome, must be explored.

The probability of obtaining the observed number of markers by chance should be calculated for the case where all loci are heterozygous in the pollen donor, because this would give the highest probability of inheriting a small number of markers and thus would be the most rigorous test. In this case, the probability of inheriting the marker at each of the loci is 0.5 , and the probability of inheriting exactly $(i-1)$ markers is $p=f_{i} / 2^{n}$, where $n$ is number of loci and $f_{i}$ is the $i$ th component of the binomial expansion for $(p+q)^{n}$, and the probability of inheriting no more than $(i-1)$ markers is:

$$
\sum_{1 \rightarrow i} f_{i} / 2^{n}
$$

If several progeny are obtained and the one with the greatest number of markers is significantly different from expectation, it is not necessary to run separate tests of probability for multiple seedlings nor to run an a posteriori test taking into account the number of progeny obtained. If $p_{1}$ is the probability that one offspring inherited no more than a certain number of markers, then the probability of obtaining $x$ progeny, none of which has inherited more than that number of markers, is $p_{1}{ }^{x}$. Because $p$ will always be between 0 and $1, p_{1}{ }^{x}$ will always be less than $p_{1}$; so, if $p_{1}$ is below 0.05 , then other hypotheses will also be below 0.05 .

\section{Results}

More than half of the pollination experiments yielded progeny but usually in small numbers. All but one of the pollination experiments yielded $<10$ progeny. Progeny were obtained from both self-pollinations and outcrosses.

AFLP analyses yielded numerous peaks. Peaks were sharp and consistent in size and position across different DNA extractions from the same leaf sample and between progeny and their pistillate parents. Peaks that were difficult to score because of overlap were excluded from the dataset. The remaining peaks included many polymorphic sites that could be used as markers distinguishing putative parents. The number of markers distinguishing putative parents varied from 23 to
68 markers (16 to 38 for the pistillate parent, and 9 to 40 staminate parent) in different pollination experiments.

Results of specific pollinations are listed by pistillate plant. Data are also summarized in Table 2.

Celtis bungeana. Pollinations were carried out on two trees of this species from different sources. Self-pollination of C. bungeana NA55278 and C. bungeana NA62994 yielded no seeds.

Pollination of $C$. bungeana NA55278 with C. occidentalis MBE (a cultivated tree growing in College Park, Md.) yielded four seedling progeny. Twenty-one AFLP markers were identified that were present in the pollen donor but not the pistillate parent and 22 markers that were present in the pistillate parent but not the pollen donor. The four progeny had all 22 of the pistillate markers but none of the staminate markers, indicating that all were selfs.

Celtis Koraiensis NA60281. Two pollinations were carried out on a single tree of this species. Neither self-pollination nor pollination with $C$. occidentalis Blandy ("Blandy" refers to trees from a wild population at the Orland E. White Arboretum of Blandy Farm, Boyce, Va.) yielded any seeds.

Celtis laEvigata BLandy 84-890. Self-pollination of this tree yielded no fruit.

Celtis occidentalis Blandy 34-2363. Self-pollination of this tree yielded nine seedlings, while no seeds resulted from pollination with $C$. laevigata Blandy.

Celtis occidentalis MBE. Celtis occidentalis MBE was pollinated with $C$. koraiensis NA60281. The pollen recipient was a single tree, not close to any other Celtis individuals, and the branches were pollinated but not bagged. One seedling progeny resulted. Fifteen AFLP markers were identified that were present in the pollen donor but not the pistillate parent and 31 markers that were present in the pistillate parent but not the pollen donor. The single progeny had 23 of the 31 pistillate markers and nine of the 15 staminate markers, indicating that it is a hybrid.

CEltis Reticulata NA62998. Three shrubs from this seedlot flowered; all were used for pollinations.

Two individuals of $C$. reticulata NA62998 were pollinated with $C$. koraiensis 60281, yielding a total of four progeny. Twenty-four AFLP markers were identified that were present in the pollen donor but not $C$. reticulata NA62998.001; 26 that were present in the pollen donor but not $C$. reticulata NA62998.002; 32 markers that were present in $C$. reticulata NA62998.001 but not the pollen donor; and 38 that were present in C. reticulata NA62998.002 but not the pollen donor. Three of the progeny had all of the maternal markers and none of the paternal markers; these were clearly selfs. The fourth had 29 of the 32 female markers and three of the 24 male markers. The probability of any offspring of the pollen donor inheriting no more than three of the 24 paternal markers is $P=0.0001386$, so the hypothesis that this plant is a hybrid must be rejected.

Three individuals of $C$. reticulata NA62998 were pollinated with $C$. occidentalis $\mathrm{MBE}$, yielding a total of nine progeny. Nine AFLP markers were identified that were present in the pollen donor but not $C$. reticulata NA62998.001 and 16 that were present in the pollen donor but not $C$. reticulata NA62998.004; 16 markers were present in $C$. reticulata NA62998.001 but not the pollen donor; and 18 were present in $C$. reticulata NA62998.004 but not the pollen donor. All nine progeny had all, or all but one, of the maternal markers. Eight 
Table 2. Results of the Celtis crossing experiments.

\begin{tabular}{|c|c|c|c|c|c|c|c|c|}
\hline Pistillate parent & Pollen source & $\begin{array}{l}\text { Bags } \\
\text { (no.) }\end{array}$ & $\begin{array}{c}\text { Selfs } \\
\text { (no. } \\
\text { progeny) }\end{array}$ & $\begin{array}{c}\text { Pistillate } \\
\text { markers } \\
\text { (no. observed } \\
\text { in progeny/no. } \\
\text { available) }\end{array}$ & $\begin{array}{c}\text { Staminate } \\
\text { markers } \\
\text { (no. observed } \\
\text { in progeny/no. } \\
\text { available) }\end{array}$ & $\begin{array}{l}\text { Hybrids } \\
\text { (no. } \\
\text { progeny) }\end{array}$ & $\begin{array}{c}\text { Pistillate } \\
\text { markers } \\
\text { (no. observed } \\
\text { in progeny/no. } \\
\text { available) }\end{array}$ & $\begin{array}{c}\text { Staminate } \\
\text { markers } \\
\text { (no. observed } \\
\text { in progeny/no. } \\
\text { available) }\end{array}$ \\
\hline C. bungeana NA55278 & Self & 1 & 0 & - & - & - & - & - \\
\hline C. bungeana NA62994 & Self & 8 & 0 & - & - & - & - & - \\
\hline C. bungeana NA55278 & $\begin{array}{l}\text { C. occidentalis } \\
\mathrm{MBE}^{\mathrm{z}}\end{array}$ & 4 & 4 & $22 / 22$ & $0 / 21$ & 0 & - & - \\
\hline C. koraiensis NA60281 & Self & 3 & 0 & - & - & - & - & - \\
\hline C. koraiensis NA60281 & $\begin{array}{l}\text { C. occidentalis } \\
\text { Blandy }\end{array}$ & 3 & 0 & - & - & - & - & - \\
\hline C. laevigata Blandy & C. laevigata Blandy & 3 & 0 & - & - & - & - & - \\
\hline C. occidentalis Blandy & Self & 10 & 9 & - & - & - & - & - \\
\hline C. occidentalis $\mathrm{MBE}$ & C. koraiensis NA60281 & $\mathrm{NB}^{\mathrm{x}}$ & 0 & - & - & 1 & $23 / 31$ & $9 / 15$ \\
\hline C. reticulata NA62998.003 & C. occidentalis $\mathrm{MBE}$ & 1 & 0 & - & - & 0 & - & - \\
\hline C. reticulata NA62998.004 & C. occidentalis $\mathrm{MBE}$ & 2 & 6 & $17-18 / 18$ & $0 / 16$ & 0 & - & - \\
\hline C. reticulata NA62998.004 & C. sinensis NA69704-J & 1 & 0 & - & - & 0 & - & - \\
\hline C. reticulata NA62998.001 & C. sinensis NA69704-J & 2 & 1 & $32 / 32$ & $0 / 28$ & 1 & $32 / 32$ & $17 / 28$ \\
\hline C. sinensis NA55093.002 & C. koraiensis NA60281 & 2 & 3 & $21-22 / 22$ & $0 / 17$ & 0 & - & - \\
\hline C. sinensis NA55093.002 & C. occidentalis $\mathrm{MBE}$ & 2 & 29 & $25-28 / 28$ & $0-1 / 40$ & 0 & - & - \\
\hline C. sinensis NA55093.001 & C. occidentalis $\mathrm{MBE}$ & 2 & 22 & $21-30 / 30$ & $0-3 / 37$ & 0 & - & - \\
\hline C. tenuifolia NA62999 & Self & 2 & 7 & - & - & 一 & - & - \\
\hline C. tenuifolia NA62999 & C. koraiensis NA60281 & 1 & 2 & $16 / 17$ & $0 / 19$ & 0 & - & - \\
\hline C. tenuifolia NA62999 & C. occidentalis $\mathrm{MBE}$ & 1 & 0 & - & - & 0 & - & - \\
\hline C. tenuifolia NA62999 & C. sinensis NA69704-J & 1 & 0 & - & - & 0 & - & - \\
\hline
\end{tabular}

${ }^{\mathrm{z}} \mathrm{A}$ cultivated tree growing in College Park, Md.

${ }^{\mathrm{y}}$ Blandy $=$ trees in a wild population at the Orland E. White Arboretum of Blandy Farm, Boyce, Va.

${ }^{\mathrm{x}} \mathrm{NB}=$ not bagged.

of the 9 lack all of the paternal markers; the ninth had a single peak that was found in the pollen donor but not in the pistillate parent. The probability of any offspring of the pollen donor inheriting no more than one of the nine paternal markers is $P=0.0195$, so the hypothesis that this plant is a hybrid must also be rejected. All nine progeny must be products of selfpollination; the single unexpected marker in one plant probably resulted from recombination.

One individual of $C$. reticulata NA62998 was pollinated with $C$. sinensis NA69704-J, yielding two progeny. Twentyeight AFLP markers were identified that were present in the pollen donor but not the pistillate parent and 32 markers that were present in the pistillate parent but not the pollen donor. One of the progeny had all of the maternal markers and none of the paternal markers; it is clearly a self. The other had all of the maternal markers and 17 of the 28 paternal markers, indicating it is a hybrid (Fig. 1).

CELtis SINENSIS NA55093. Two trees from this seedlot are planted near one another; both were used for pollinations.

Pollination of $C$. sinensis NA55093.002 with $C$. koraiensis NA60281 yielded three progeny. Sixteen AFLP markers were identified that were present in the pollen donor but not the pistillate parent and 22 markers that were present in the pistillate parent but not the pollen donor. The three progeny had 21 or 22 of the pistillate markers, and none of the staminate markers, indicating that none were hybrids. All three of the progeny had markers from $C$. sinensis NA55093.001, indicating that all resulted from contamination with air-borne pollen from the other tree when slits were cut in the bags for pollination.

Pollination of the two $C$. sinensis NA55093 with C. occidentalis MBE yielded 51 progeny. Thirty-seven AFLP markers were identified that are present in the pollen donor but not $C$. sinensis NA55093.001; 40 that are present in the pollen donor but not $C$. sinensis NA55093.002; 30 markers that are present in $C$. sinensis NA55093.001 but not the pollen donor; and 28 that are present in C. sinensis NA55093.002 but not the pollen donor. Six AFLP markers were found to differentiate the two trees of $C$. sinensis NA55093. All 51 of the progeny had markers from both trees of $C$. sinensis NA55093, indicating that all resulted from contamination with air-borne pollen from the other tree when the bags were opened for pollination. Seven of the progeny each had a single peak that was absent from both $C$. sinensis NA55093 but present in $C$. occidentalis $\mathrm{MBE}$, and one had three such markers. The probability of any offspring of the pollen donor inheriting no more than three of the 22 paternal markers is $P=0.0004277$, so the hypothesis that this is a hybrid with $C$. occidentalis must be rejected. The presence of peaks from the two adjacent trees of $C$. sinensis suggests that they all are the product of cross pollination between these two trees. 
CELtis tenuifolia NA62999. Four separate pollinations were carried out on a single tree of this accession. Selfpollination yielded seven seeds. Pollination with C. occidentalis MBE and with $C$. sinensis NA55093 yielded no progeny. Pollination with $C$. koraiensis NA60281 yielded two progeny. Nineteen AFLP markers were identified that were present in the pollen donor but not the pistillate parent, and 17 markers that were present in the pistillate parent but not the pollen donor. The two progeny had 16 and 17 of the pistillate markers, respectively, but none of the staminate markers, indicating that both were selfs.

Overall. Of the 76 progeny obtained, only two individuals have the AFLP profile expected for $F_{1}$ interspecific hybrids, that is, more than half of the markers characteristic of the pollen parent (nine of 15 and 17 of 28 , both $\approx 60 \%$ ).

Of the other 74 progeny, 64 have no paternal markers. The other 10 had small numbers of unexpected AFLP fragments: eight had only a single fragment found in the pollen donor but not the pistillate parent, and two had three such fragments. These 14 anomalous peaks represented nine different fragments, amplified by five different primer pairs. In all cases, the hypothesis that these are actually hybrids and the small number of paternal markers inherited is due to random assortment within the paternal genotype could be rejected confidently. This
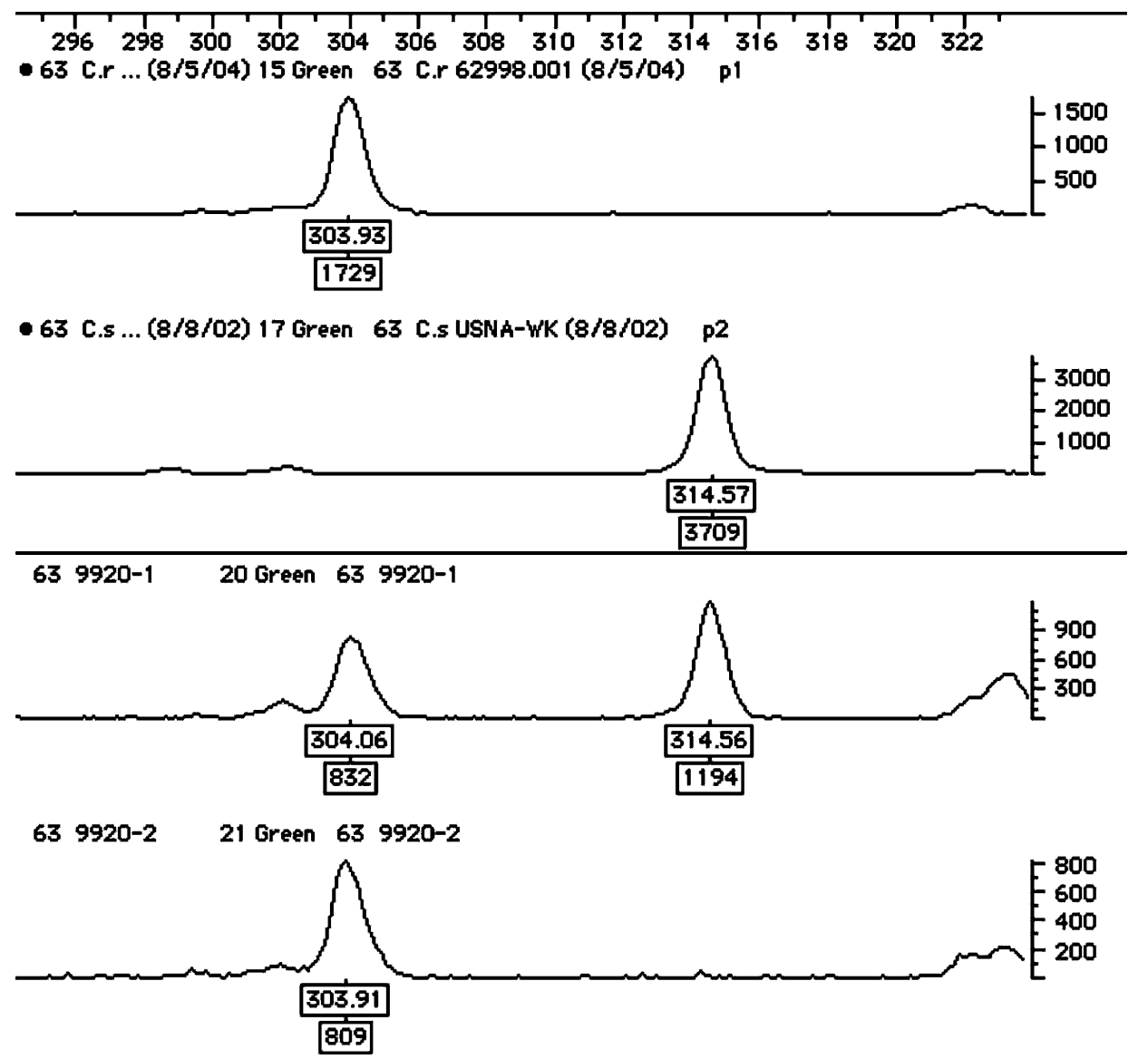

Fig. 1. Representative portions of AFLP traces for primer pair 63 on four plants. Top trace: The maternal parent, $C$. reticulata NA62998, showing an AFLP fragment 304 bp long (a maternal marker). Second trace: The putative paternal parent, C. sinensis NA69704-J, showing an AFLP fragment 315 bp long (a paternal marker). Third trace: The putative hybrid, showing both markers. Fourth trace: The putative self, showing only the maternal marker. conclusion is reinforced by the fact that eight of the 10 progeny with anomalous peaks resembling the pollen donor were offspring of $C$. sinensis NA55093 that showed markers for a neighboring $C$. sinensis, indicating that these seedlings resulted from contamination with air-borne pollen from the other tree when slits were created in the bags for pollination. The overall percentage of anomalous peaks was very low: the total number of staminate markers scored for all 74 progeny was 2398 ( 9 to 40 per plant, depending on the specific cross attempted), and 14 anomalous peaks were observed, for a frequency of 0.0058 , or one of every 171 peaks scored.

Both of the hybrids obtained are very slow-growing, and neither has flowered. As is usual for Celtis, both show an apparently juvenile leaf morphology. The long persistence of a juvenile leaf morphology that is often very different from the adult leaf morphology poses a problem with using morphology to identify young hybrids in Celtis, and this is exacerbated by the slow growth of these two hybrids, which prolongs the juvenile phase even longer than usual. The plant of C. occidentalis $\times$ C. koraiensis has oblong-elliptical leaves with a slenderly acuminate apex, and the margin serrate all around with large, triangular marginal teeth that are very irregular in size. The leaf shape is somewhat intermediate between juvenile leaves of the parents, and the marginal teeth are intermediate between the smaller, more regular serrations of $C$. occidentalis and the very large, irregular laciniate teeth of $C$. koraiensis. The plant of $C$. sinensis $\times$ C. reticulata is growing even more slowly. It has oblong, rough, strongly toothed leaves, representing a typical juvenile leaf morphology in this group and not similar to adult leaves of either parent. However, the leaves and stems are covered with straight, spreading, pale brown hairs that are clearly intermediate between the spreading white hairs of C. reticulata and the curved brown hairs of $C$. sinensis, so both hybrids show at least some evidence of morphological intermediacy.

\section{Discussion}

Hybrids were formed very rarely among the seven species of Celtis that were cross-pollinated in this study. This study, like that of Whittemore (2005), did not support the earlier view that species of Celtis hybridize easily. Self-pollination produced a few seeds, but it is doubtful that the small number of selfs observed had much influence on the low level of interspecific hybridization. Both $C$. occidentalis Blandy and C. tenuifolia yielded considerably more seed when selfpollinated with a paint brush than 
they did when only pollen from other species was applied to the stigmas, suggesting that selfing may have been limited by limited movement of pollen within bags. Contamination with air-borne pollen from other individuals of the same species produced many more progeny, and it seems quite possible that reopening bags after cross pollination to ensure complete emasculation would cause more nonhybrid seed set due to contamination with wind-borne pollen than allowing self pollen to dehisce in the presence of the stigmas. In addition, there is some evidence that at least some species of Celtis are capable of apomixis, so some of the seeds listed as selfs could actually be apomicts.

It is possible that further experimentation with procedures for pollen storage and handling might also improve the rate of hybrid formation. Work on procedures for pollen storage and handling is being carried out, and preliminary results indicate that pollen stored using our methods will germinate on Marquard's (1992) medium, although germination rates are lower than in many tree genera.

AFLP analysis yielded false paternal markers at a very low frequency. It seems most likely that these fragments represent differences in DNA methylation within the EcoRI and $M s e I$ restriction sites. DNA methylation has been shown to affect AFLP profiles in other taxa (Fang et al., 2005). The very low overall percentage of anomalous peaks $(0.0058)$ is not an unreasonable level for methylation differences. These peaks do not seem to be incited by contamination with fungi or insects. Such contamination with whole foreign genomes would yield groups of co-occurring peaks that would appear together in certain samples. In our data, 8 of the 10 samples with unexpected markers had only 1 (the other 2 had 3 each), and the 14 unexpected peaks represent 9 different primer fragment length combinations. Other causes, such as recombination or the mobilization of transposons, seem much less likely than methylation differences, but they cannot be ruled out.

Despite the rare false paternal markers, AFLP analysis was very effective for identifying paternity of young plants. Genuine hybrids yielded markers in expected frequencies (dominant alleles inherited at half or more of the loci examined), and samples with low levels of paternal markers could be ruled out confidently by calculating the probability of obtaining such low frequencies. However, the study clearly demonstrated the importance of using large numbers of markers, because frequency calculations would not attain significance in a sample with few loci.

\section{Literature Cited}

Boonpragob, K. 1972. Crossing within the genus Celtis (Ulmaceae). J. Tennessee Acad. Sci. 47(2):54 (abstr.).

Dirr, M.A. 1998. Manual of woody landscape plants. 5th ed. Stipes Publishing, Champaign, Ill.

Elias, T.S. 1970. The genera of Ulmaceae in the southeastern United States. J. Arnold Arboretum 51:18-40.

Fang, J.-G., C.-C. Chao, R.J. Henny, and J.-J. Chen. 2005. DNA methylation polymorphisms in somaclonal-derived cultivars of ornamental aroids. HortScience 40:1105 (abstr.).

Fernald, M.L. 1950. Manual of botany. 8th ed. Van Nostrand, New York.

Krajicek, J.E. 1965. Hackberry (Celtis occidentalis L.), p. 140-143. In: H.A. Fowells (ed.). Silvics of forest trees of the United States. U.S. Department of Agriculture, Agriculture Handbook 271. Washington, D.C.

Krajicek, J.E. and R.D. Williams. 1990. Celtis occidentalis, p. 262 265. In: R.M. Burns and B.H. Honkala (eds.), Silvics of North America, Vol 2. Hardwoods. Agriculture Handbook 654. U.S. Department of Agriculture, Forest Service, Washington, D.C.

Mabberley, D.J. 1997. The plant-book. 2nd ed. Cambridge University Press, New York.

Marquard, R.D. 1992. Pollen tube growth in Carya and temporal influence of pollen deposition on fertilization success in pecan. J. Amer. Soc. Hort. Sci. 117:328-331.

Mitchell, R.S. 1988. Platanaceae through Myricaceae of New York State. Contributions to a flora of New York State VI. New York State Museum Bul. No. 464. State Education Department, Albany, N.Y.

Pooler, M.R., G.H. Riedel, S.E. Bentz, and A.M. Townsend. 2002. Molecular markers used to verify interspecific hybridization between hemlock (Tsuga) species. J. Amer. Soc. Hort. Sci. 127:623-627.

Song, B.-H., X.-Q. Wang, F.-Z. Li, and D.-Y. Hong. 2001. Further evidence for paraphylly of the Celtidaceae from the chloroplast gene matK. Plant Syst. Evol. 228:107-115.

Sytsma, K.J., J. Morawetz, J.C. Pires, M. Nepokroeff, E. Conti, M. Zjhra, J.C. Hall, and M.W. Chase. 2002. Urticalean rosids: circumscription, rosid ancestry, and phylogenetics based on rbcL, trnL-F, ndhF sequences. Amer. J. Bot. 89(9):1531-1546.

Vos, P., R. Hogers, M. Bleeker, M. Reijans, T. van de Lee, M. Hornes, A. Frijters, J. Pot, J. Peleman, M. Kuiper, and M. Zabeau. 1995. AFLP: a new technique for DNA fingerprinting. Nucleic Acids Res. 23:4407-4414.

Whittemore, A.T. 2005. Genetic structure, lack of introgression, and taxonomic status in the Celtis laevigata-C. reticulata complex (Celtidaceae). Syst. Bot. 30:809-817.

Wiegrefe, S.J., K.J. Sytsma, and R.P. Guries. 1998. The Ulmaceae, one family or two? Evidence from chloroplast DNA restriction site mapping. Plant Syst. Evol. 210:249-270.

Wofford, B.E. and E.W. Chester. 2002. Guide to the trees, shrubs, and woody vines of Tennessee. University of Tennessee Press, Knoxville. 